\title{
The Effect of Substrate Temperature on The Structure and Morphologies of PbS Thin Films Deposited by Ultrasonic Spray Pyrolysis
}

\author{
Emrah Sarıca $^{1 * i D}$, Vildan Bilgin ${ }^{2}$ \\ 1 Bursa Technical University, Department of Physics, 16310 Bursa, Turkey \\ ${ }^{2}$ Canakkale Onsekiz Mart University, Department of Physics, 17020 Çanakkale, Turkey
}

\begin{abstract}
Cite this paper as:
Sarica, E., Bilgin, V.,(2019). The Effect of Substrate Temperature on The Structure and Morphologies of PbS Thin Films Deposited by Ultrasonic Spray Pyrolysis Turkey. Journal of Innovative Science and Engineering. 3(2): 66-72
\end{abstract}

*Corresponding author: Emrah Sarıca E-mail: emrah.sarica@btu.edu.tr Tel: +90 (224) 3003669

Received Date: 02/11/2019

Accepted Date: 22/12/2019

(C) Copyright 2019 by

Bursa Technical University. Available online at http://jise.btu.edu.tr/

\section{(c) (i) (9)}

The works published in Journal of Innovative Science and Engineering (JISE) are licensed under a Creative Commons Attribution-NonCommercial 4.0 International License.

\begin{abstract}
In this work, we aimed to deposit $\mathrm{PbS}$ thin films at relatively low temperature and therefore thin films were deposited onto preheated glass substrates at $473 \mathrm{~K}$ and $523 \mathrm{~K}$ by ultrasonically spraying of equimolar aqueous solution of lead acetate and thiourea. The thickness of deposited thin films was determined by spectroscopic ellipsometry (SE) prior to investigate physical properties of deposited $\mathrm{PbS}$ films. In order to investigate structural and morphological properties of $\mathrm{PbS}$ thin films, $\mathrm{x}$-ray diffraction (XRD) patterns and Atomic Force Microscopy (AFM) images were obtained. Crystal structure, mean crystallite size, lattice parameters, micro-strain of deposited thin films were evaluated by means of XRD patterns and it was seen that deposited PbS thin films were successfully obtained in polycrystalline form with cubic crystal structure. Also lattice parameter of a was calculated as $5.866 \AA$ and $5.870 \AA$ for thin films deposited at $473 \mathrm{~K}$ and $523 \mathrm{~K}$, respectively. Additionally, the surface roughness of PbS thin films was determined via AFM images as $5.8 \mathrm{~nm}$ and $9.9 \mathrm{~nm}$ in non-contact mode. The obtained results confirm that deposition of $\mathrm{PbS}$ thin films can be successfully achieved at relatively low temperature.
\end{abstract}

Keywords: Ultrasonic Spray Pyrolysis, PbS Thin Films, Structural Properties, Morphological Properties 


\section{Introduction}

Because of their adjustable physical properties, semiconductor materials attract great interest in scientific and technological applications. One of the most attractive semiconducting material is lead sulfide $(\mathrm{PbS})$ which is a member of IV-VI metal chalcogenides. PbS has quite small direct band gap $(0.41 \mathrm{eV}$ at $300 \mathrm{~K})$ in bulk form [1]. However, for the nanosized form, optical absorption edge shifts from infrared to visible region due to strong quantum confinement effect because of its larger Bohr radius ( 18 nm) [2]. In general, undoped $\mathrm{PbS}$ have p-type electrical conductivity [3]. Considering all these mentioned unique properties, $\mathrm{PbS}$ have wide range of application fields including infrared detectors [4], gas sensors [5] diode lasers [6] thin film solar cells [7] etc.

$\mathrm{PbS}$ thin films can be deposited by adopting various techniques such as DC sputtering [8], RF sputtering [9], vacuum evaporation [10] chemical bath deposition (CBD) [3], spray pyrolysis [11] etc. In this work, spray pyrolysis equipped with ultrasonic nozzle was used to deposit thin film due to its simplicity and practicality. This technique is based on spraying aqueous solutions of chemical salts prepared at certain concentrations and volumes onto pre-heated substrates at certain flow rates and durations in accordance with the thin films desired to be deposited. Thin film deposition process with spray pyrolysis technique consists of three basic steps in order of atomization of solution, transport of atomized droplets and decomposition [12, 13]. Physical properties of thin films deposited by using this technique tightly depends on precursor compositions and solution molarity, used solvent and chemical salts, distance between nozzle and substrate, solution flow rate, substrate temperature, spray duration, type and pressure of carrier gas [14].

\section{Methods}

\subsection{Preparation of Precursor Solution}

For the deposition of $\mathrm{PbS}$ thin films, $100 \mathrm{ml}$ of precursor aqueous solutions which contain $0.05 \mathrm{M}$ lead acetate $\left[\mathrm{Pb}\left(\mathrm{CH}_{3} \mathrm{CO}_{2}\right)_{2} .3 \mathrm{H}_{2} \mathrm{O}\right]$ and $0.05 \mathrm{M}$ thiourea $\left[\mathrm{CH}_{4} \mathrm{~N}_{2} \mathrm{~S}\right]$ were prepared using deionize water $(\mathrm{DI})$ as solvent. All precursor solution was not subject to any further aging process and freshly prepared before each deposition.

\subsection{Deposition of PbS Thin Films}

Prior to deposition, cleaning of glass substrates realized as given in [15] Ultrasonic spray pyrolysis technique was used to deposit $\mathrm{PbS}$ thin films. Details about deposition technique was given in [16]. In present study, a total of $100 \mathrm{ml}$ precursor solution was sprayed onto the glass substrates for $20 \mathrm{~min}$ with a flow rate of $5 \mathrm{ml} / \mathrm{min}$. For the atomization of solution, ultrasonic atomizer nozzle that works at $100 \mathrm{kHz}$ frequency was used. The distance between the nozzle and the substrate was maintained at $35 \mathrm{~cm}$ and compressed air with a pressure of $1 \mathrm{~atm}$ was used as carrier gas. To investigate the effect of substrate temperature on the physical properties of $\mathrm{PbS}$ thin films, all the above-mentioned parameters were kept constant except the substrate temperature which was adjusted as $473 \mathrm{~K}$ and $523 \mathrm{~K}$ and controlled within $\pm 5^{\circ} \mathrm{C}$ by using an iron-constantan thermocouple. 


\subsection{Characterization Techniques}

First of all, thickness value of PbS thin films was determined by using PHE 102 Spectroscopic Ellipsometry and found to be $551 \mathrm{~nm}$ and $487 \mathrm{~nm}$ for thin films deposited at $473 \mathrm{~K}$ and $523 \mathrm{~K}$, respectively. The structural investigations of the films were carried out by using X-ray diffractometer (PANalytical Empyrean), having CuK $\alpha$ radiation ( $\lambda=1.5405 \AA$ ). For the morphological evaluations, The AFM images were obtained by using Park System XE 70 Atomic Force Microscope.

\section{Results and Discussion}

\subsection{Structural Studies}

$\mathrm{X}$-ray diffraction patterns which are used to investigated structural properties of $\mathrm{PbS}$ thin films were given in Figure 1. As it can be seen from Figure 1, all XRD patterns for PbS thin films deposited at $473 \mathrm{~K}$ and $523 \mathrm{~K}$ have a set of diffraction peaks which are indexed to fcc cubic structure of PbS by comparing Joint Committee on Powder Diffraction Standards (JCPDS Card No: 65-0346) data file. Existing more than one peaks on XRD patterns indicates that PbS thin films are in polycrystalline form. The peaks located at $2 \theta \sim 26.3^{\circ}, 30.4^{\circ}, 43.5^{\circ}, 51.4^{\circ}, 53.8^{\circ}, 62.9^{\circ}$ are indexed as (111), (200), (220), (311), (222) and (400) crystal planes.

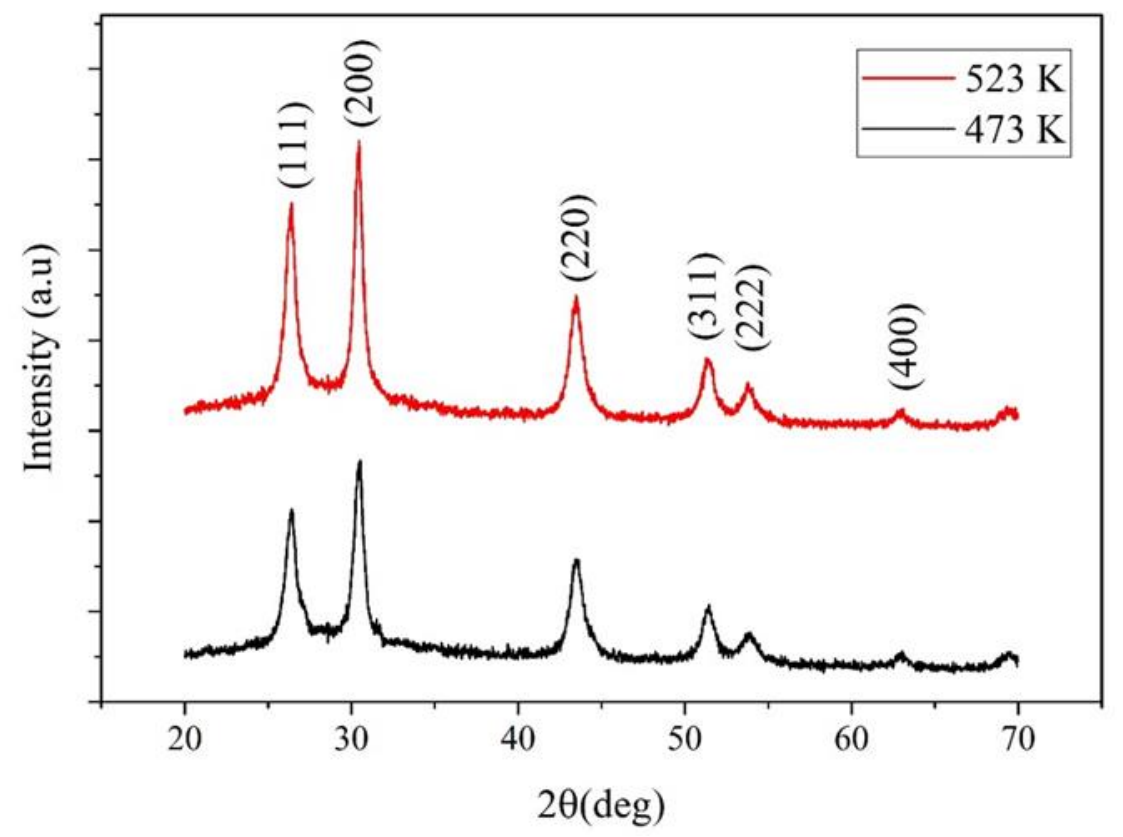

Figure 1. XRD patterns of PbS thin films deposited at $473 \mathrm{~K}$ and $523 \mathrm{~K}$. 
The position of diffraction angles, full wide half maxima (FWHM) of peaks, interplanar spacing (d) were extracted from XRD patterns and tabulated in Table 1. As it can be seen from Table 1, FWHM values belonging to three predominant peaks which exist on XRD patterns slightly decreases when substrate temperature increases from $473 \mathrm{~K}$ to $523 \mathrm{~K}$. This may indicate the mean crystallite size of polycrystalline $\mathrm{PbS}$ thin films increases with the deposition temperature. The mean crystallite size of $\mathrm{PbS}$ thin films was calculated by applying Debye-Scherr's equation [17] on the highest diffraction peak (200) and listed in Table 1.

$D=0.94 \lambda / \beta \cos \theta$

where $\lambda$ is the wavelength of the $\mathrm{x}$-ray used, which is $0.15406 \mathrm{~nm}, \theta$ is the Bragg angle and $\beta$ is the FWHM (in radians). The mean crystallite size of the PbS thin films was found to be $12 \mathrm{~nm}$ and $13 \mathrm{~nm}$ for PbS films deposited at $473 \mathrm{~K}$ and $523 \mathrm{~K}$, respectively. Not only instrumental broadening and crystallite size contribute broadening of diffraction peaks but also micro strain which exist through thin films makes contribution. Therefore, we may estimate micro-strain $(\varepsilon)$ formed in thin films by using following equation for highest diffraction peak (200) [18],

$\varepsilon=\beta \cot \theta / 4$

Based on above equation, micro-strain values belonging to thin films were calculated as $1.12 \times 10^{-2}$ and $1.04 \times 10^{-2}$.

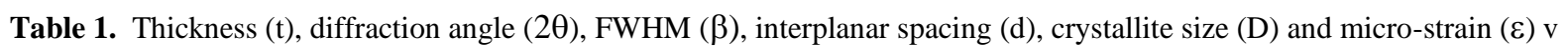
alues of deposited $\mathrm{PbS}$ thin films.

\begin{tabular}{|c|c|c|c|c|c|c|c|c|c|}
\hline \multirow{2}{*}{$\begin{array}{l}\text { Substrate } \\
\text { Temp. } \\
\text { (K) }\end{array}$} & \multirow[b]{2}{*}{$\mathbf{t}(\mathbf{n m})$} & \multirow[b]{2}{*}{$2 \theta\left({ }^{\circ}\right)$} & \multirow[b]{2}{*}{$\beta\left(^{\circ}\right)$} & \multirow[b]{2}{*}{ d $(\AA ̊)$} & \multirow[b]{2}{*}{ a $(\AA ̊)$} & \multicolumn{2}{|c|}{ D (nm) } & \multicolumn{2}{|c|}{$\varepsilon\left(\times 10^{-2}\right)$} \\
\hline & & & & & & Scherrer & W-H (nm) & Eq. (2) & W-H \\
\hline \multirow{3}{*}{473} & \multirow{3}{*}{551} & 26.38 & 0.854 & 3.376 & 5.847 & 10 & \multirow{3}{*}{13} & 1.59 & \multirow{3}{*}{0.169} \\
\hline & & 30.45 & 0.699 & 2.933 & 5.866 & 12 & & 1.12 & \\
\hline & & 43.52 & 1.065 & 2.078 & 5.877 & 8 & & 1.16 & \\
\hline \multirow{3}{*}{523} & \multirow{3}{*}{487} & 26.35 & 0.780 & 3.380 & 5.853 & 11 & \multirow{3}{*}{17} & 1.45 & \multirow{3}{*}{0.370} \\
\hline & & 30.43 & 0.646 & 2.935 & 5.870 & 13 & & 1.04 & \\
\hline & & 43.48 & 0.995 & 2.080 & 5.882 & 9 & & 1.09 & \\
\hline
\end{tabular}

Williamson-Hall (W-H) method is another approach to find out more realistic crystallite size and micro-strain. Total broadening in diffraction peak is the sum of broadening due to crystallite size $(\beta C)$ and broadening due to strain ( $\beta S)$ $[19,20]$. 
By assuming that the particle size and strain contributions to broadening are independent to each other and the strain is uniform in all directions, then the total broadening of diffraction peak can be expressed as

$\beta \cos \theta=\lambda / \mathrm{D}+4 \varepsilon \sin \theta$

Therefore, by constructing plot of $\beta \cos \theta$ vs. $4 \sin \theta$ given in Figure 2, crystallite size (D) and micro-strain ( $\varepsilon$ ) can be extracted from y-intercept and the slope of the linear fit, respectively [19, 20, 21].

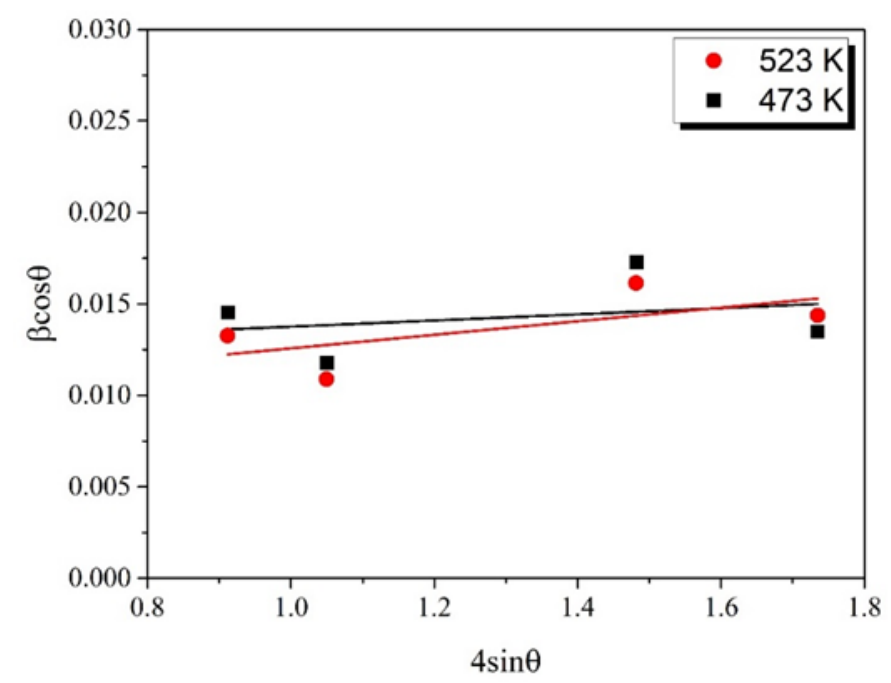

Figure 2. Williamson-Hall plots of PbS thin films deposited at $473 \mathrm{~K}$ and $523 \mathrm{~K}$.

As it can be seen from the Table 1, the mean crystallite size values were extracted from W-H plots as $13 \mathrm{~nm}$ and $17 \mathrm{~nm}$ for PbS thin films deposited at $473 \mathrm{~K}$ and $523 \mathrm{~K}$, respectively. However, these results are slightly different from the calculated by Debye-Scherrer equation due the difference in averaging the particle size distribution [21].

\subsection{Morphological Studies}

The surface morphology of deposited $\mathrm{PbS}$ thin films was examined by means of captured AFM images which are given in the Figure 3. The AFM images show that all the thin films were successfully deposited with the absence of voids and holes through the surface and thin films have almost homogeneous surface. They also reflect the dark and bright regions which represent hollow and hill formation were observed through the surface of all deposited films [22]. The $\mathrm{R}_{\mathrm{pv}}$ values which represent the distance between highest hill and lowest hollow increased from $60 \mathrm{~nm}$ to $86 \mathrm{~nm}$ with the increase in substrate temperature. In addition to this, average roughness of thin films (Rave) increased from $6 \mathrm{~nm}$ to $10 \mathrm{~nm}$. 

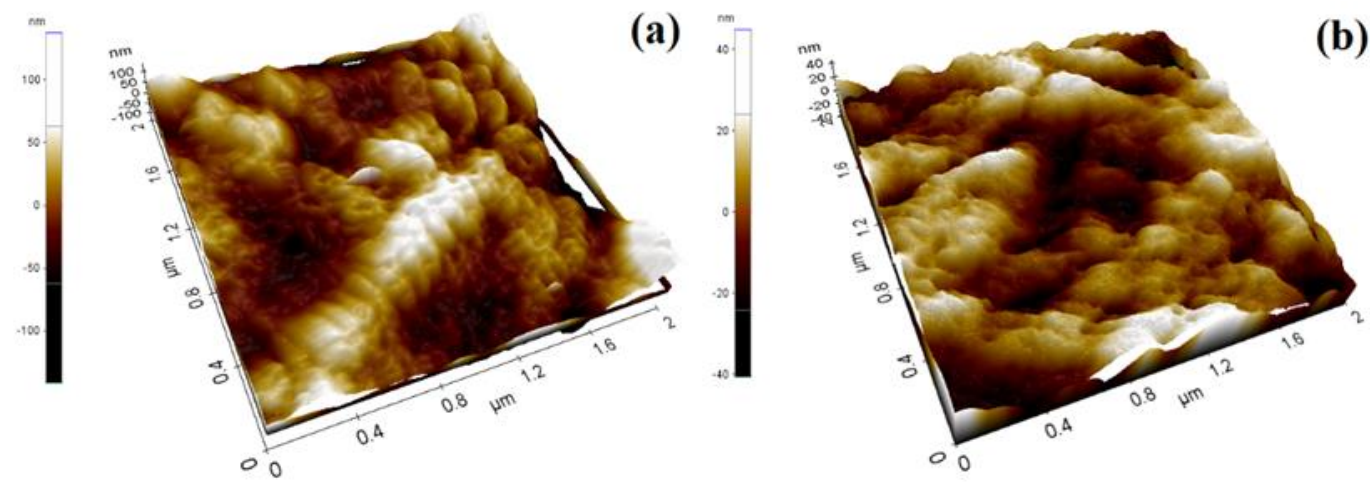

(b)

Figure 3. AFM images of PbS thin films (a) deposited at $473 \mathrm{~K}$ and (b) $523 \mathrm{~K}$

This kind of variation indicates that the surface morphologies of deposited thin films deteriorated with the increase in substrate temperature and it may be related with the sulphur losses with the substrate temperature. This needs to be proven by the elemental analysis such as EDS or XPS.

\section{Conclusion}

In the present study, we successfully deposited $\mathrm{PbS}$ thin film at $473 \mathrm{~K}$ and $523 \mathrm{~K}$ by ultrasonic spray pyrolysis to investigate the effect of substrate on the structure and morphology of PbS. XRD patterns revealed that both two thin films deposited at $473 \mathrm{~K}$ and $523 \mathrm{~K}$ have fcc cubic structure and increase in substrate temperature led to slightly enhance in crystalline. The Debye-Scherrer and Williamson-Hall approaches were used to determine mean crystalline size of thin films and found to be between $12 \mathrm{~nm}-17 \mathrm{~nm}$. Additionally, it was seen that calculated lattice parameters are slightly less than the value ( $a=5.938 \AA$ ) in JCPDS card of PbS. AFM images unveil that the surface of PbS thin films were adversely effected from the increase in substrate temperature.

\section{References}

[1]. Liu, X., Zhang, M. (2000). Studies on PbS and PbSe detectors for IR system. International journal of Infrared and Millimeter waves, 21(10):1697-1701.

[2] Zhou, R., Niu, H., Ji, F., Wan, L., Mao, X., Guo, H., Xui J., Cao, G., (2016). Band-structure tailoring and surface passivation for highly efficient near-infrared responsive $\mathrm{PbS}$ quantum dot photovoltaics. Journal of Power Sources, 333:107-117.

[3] Göde, F., Güneri, E., Emen, F. M., Kafadar, V. E., Ünlü, S. (2014). Synthesis, structural, optical, electrical and thermoluminescence properties of chemically deposited PbS thin films. Journal of Luminescence, 147:41-48.

[4] Sun, Z., Liu, Z., Li, J., Tai, G. A., Lau, S. P., Yan, F., (2012). Infrared photodetectors based on CVD-grown graphene and $\mathrm{PbS}$ quantum dots with ultrahigh responsivity. Advanced materials, 24(43):5878-5883.

[5] Bandyopadhyay, S. (2012). Performance of nanocrystalline PbS gas sensor with improved cross-sensitivity. Particulate Science and Technology, 30(1):43-54. 
[6] Ralston, R. W., Walpole, J. N., Calawa, A. R., Harman, T. C., McVittie, J. P. (1974). High cw output power in stripe-geometry PbS diode lasers. Journal of Applied Physics, 45(3): 1323-1325.

[7] Göde, F., Ünlü, S. (2019). Synthesis and characterization of CdS window layers for PbS thin film solar cells. Materials Science in Semiconductor Processing, 90: 92-100.

[8] Soetedjo, H., Siswanto, B., Aziz, I. (2018). Deposition of Cu-doped PbS thin films with low resistivity using DC sputtering. Results in physics, 8: 903-907.

[9] da Silva Filho, J. M. C., Marques, F. C. (2019). Structural and optical temperature-dependent properties of PbS thin films deposited by radio frequency sputtering. Materials Science in Semiconductor Processing, 91:188-193.

[10] Kumar, S., Sharma, T. P., Zulfequar, M., \& Husain, M. (2003). Characterization of vacuum evaporated PbS thin films. Physica B: Condensed Matter, 325:8-16.

[11] Rosario, S. R., Kulandaisamy, I., Kumar, K. D. A., Arulanantham, A. M. S., Valanarasu, S., Youssef, M. A., Awwad, N. S. (2019). Deposition of p-type Al doped PbS thin films for heterostructure solar cell device using feasible nebulizer spray pyrolysis technique. Physica B: Condensed Matter, 411704.

[12] Perednis, D., Gauckler, L. J. (2005). Thin film deposition using spray pyrolysis. Journal of electroceramics, 14(2), 103-111.

[13] Filipovic, L., Selberherr, S., Mutinati, G. C., Brunet, E., Steinhauer, S., Köck, A., Schrank, F. (2013, July). Modeling spray pyrolysis deposition. In Proceedings of the world congress on engineering . 2:987-992.

[14] Ardekani, S. R., Aghdam, A. S. R., Nazari, M., Bayat, A., Yazdani, E., Saievar-Iranizad, E. (2019). A comprehensive review on ultrasonic spray pyrolysis technique: Mechanism, main parameters and applications in condensed matter. Journal of Analytical and Applied Pyrolysis, 104631.

[15] Sarica E., BilginV., (2017). Study of some physical properties of ultrasonically spray deposited silver doped lead sulphide thin films. Materials Science in Semiconductor Processing, 68, 288-294.

[16] Atay F., Bilgin V., Akyuz I., Kose, S., (2003). The effect of In doping on some physical properties of CdS films, Materials Science in Semiconductor Processing, 6:197-203.

[17] Cullity B.D., (1956). Elements of X-ray Diffraction. Addison-Wesley Publishing Company, Inc., USA.

[18] Kumar R., Das R., Gupta M., Ganesan V., (2014). Preparation of nanocrystalline Sb doped PbS thin films and their structural, optical, and electrical characterization, Superlattices and microstructures. 75:601-612.

[19] Rashad M. M., Fouad O.A., (2014). Solvothermal growth of Ti1-xSnxO2 semiconductor nanopowders. Applied Nanoscience, 4(3), 379-383.

[20] Turgut G., (2018) Evaluation of Nd-Loaded SnO2:F Films Coated via Spray Pyrolysis. Journal of Electronic Materials, 47(7):4149-4155.

[21] Mote, V. D., Purushotham, Y., Dole, B. N. (2012). Williamson-Hall analysis in estimation of lattice strain in nanometer-sized $\mathrm{ZnO}$ particles. Journal of Theoretical and Applied Physics, 6(1):6.

[22] Sarica, E., Bilgin, V., (2017). Effect of Pb: S molar ratio in precursor solution on the properties of lead sulphide thin films by ultrasonic spray pyrolysis. Materials Science in Semiconductor Processing, 71: 42-49. 